\title{
REFLEXÕES SOBRE A CONDIÇÃO PERIFÉRICO-ESTRATÉGICA DA FRONTEIRA AMAPAENSE
}

\author{
Jadson Luís Rebelo Porto ${ }^{1}$
}

\begin{abstract}
Resumo
O artigo trata da condição periférico-estratégica do estado do Amapá e sua inserção no Planalto das Guianas, relembrando as etapas do processo de integração nacional da Amazônia a partir da década de 1970, sob os discursos de "integrar para não entregar". Nas décadas subseqüentes, vários fatores começaram a mudar a condição de periferia do Estado: a instalação do Complexo Industrial do Jari, no sul do Amapá; a construção da rodovia BR-156 (de 1970 a 1980), ligando Oiapoque até o Laranjal do Jari; a mudança de comportamento entre vizinhos internacionais, principalmente representado pelo Acordo-Quadro entre Brasil e França (1995) e a previsão da entrega da Ponte Fronteiriça construída entre a Guiana e o Brasil. Por fim o artigo aponta indicativos do aumento da conectividade externa do estado do Amapá: o aumento do comércio atacadista; a instalação da Área de Livre Comércio de Macapá e Santana (1990) - uma das sete Áreas de Livre Comércio instaladas na Região Amazônica e a criação da Zona Franca Verde 2008, localizada no município de Santana.
\end{abstract}

Palavras-chave: Condição Periférico-estratégica do Amapá. Integração Nacional. Mudança da Condição Periférica. Aumento da Conectividade Externa.

\begin{abstract}
The article deals with the peripheral-strategic condition of Amapá state and its insertion in the Guiana Plato, recalling the steps in the process of national integration of the Amazon from the 1970s, under the discourse to "integrate to not give up". In subsequent decades, several factors began to change the status on the periphery of the state: the installation of the Jari Industrial Complex, south of Amapá; the construction of highway BR-156 (1970 to 1980), linking Oiapoque to Laranjal do Jari; the change of behavior between international neighbors, mainly represented by the Framework Agreement between Brazil and France (1995) and forecast of the delivery of the Border Bridge built between Guyana and Brazil. Finally the article points indicative of increased external connectivity of Amapá state: the increase in wholesale trade; the installation of the Free Trade Area of Macapá and Santana (1990) one of the seven installed Free Trade Areas in the Amazon region - and creation of the Zona Franca Verde 2008, located in Santana.
\end{abstract}

Keywords: Peripheral-strategic Condition of Amapá. National Intregration. Changing of the Peripheral Condition. Increasing the External Connectivity.

\footnotetext{
${ }^{1}$ Licenciado e Bacharel em Geografia. Mestre em Geografia pela Universidade Federal de Santa Catarina. Doutor em Ciências Econômicas pela Universidade Estadual de Campinas (2002). Atualmente, é professor Associado da Universidade Federal do Amapá, docente do Mestrado em Desenvolvimento Regional. www.unifap.br/professor/jadsonporto; http://twitter.com/percepcoe-samapa Email: jadsonporto@yahoo.com.br
} 
Inicialmente, agradeço ao convite do professor Aldomar Rückert, e espero poder colaborar com algumas "elucubrações" dos nossos estudos na Fronteira com a Guiana Francesa, em uma discussão que temos chamado de Condição Fronteiriça. Esse termo, eu ouvi pela primeira vez através da professora Adriana Doffmann em Montevidéu, durante o Encontro de Geógrafos da América Latina (2009), e me senti extremamente provocado, considerando a relação inversa das interações fronteiriças amapaenses com a Guiana Francesa.

Em 2008, participamos de uma expedição pela fronteira do Uruguai, e uma das questões que a professora Lia Osório (UFRJ) fazia em cada momento que parávamos foi a questão do pertencimento da Fronteira. Não me preocupei em discutir o pertencimento, mas me preocupei em tentar entender de que maneira a questão histórica da região foi sendo trabalhada ao longo dos anos.

Constantemente, ouvimos falar que a Amazônia é periferia. Foi daí que comecei a rever alguns textos, e o meu ponto de partida foi uma obra do professor João Manoel Cardoso de Mello (Unicamp) (1998), que identificou o Brasil com um Capitalismo Tardio, e o professor Francisco da Costa (UFPA) identificou a Amazônia com um Capitalismo Tardio Periférico. E eu tenho cunhado que, no caso específico do Amapá, este apresenta um Capitalismo Tardio Periférico da Periferia. E, neste entendimento, temos dois olhares, no mínimo. E sob esses dois olhares, vamos trabalhar. Ei-los: um olhar periférico e um estratégico.

Até a década de 1960, a Região Amazônica não tinha uma conectividade muito fluida. As rodovias estavam recém-construídas, não pavimentadas; as relações espaciais davam-se basicamente pelos rios. Quando chegou a década de 1970, sob os discursos de "integrar para não entregar" e conduzir "Homens sem Terras para Terras sem Homens", ações governamentais foram executadas (re)formatando o espaço amazônico.

A figura 1 é uma propaganda do Banco da Amazônia e do Ministério do Interior divulgada na Revista Veja, em 1970. Vejam o lema usado pelo Governo Federal para estimular a integração, concedendo os incentivos fiscais e outros mais. 
Fig. 01. Propaganda para atrair investidores para Amazônia

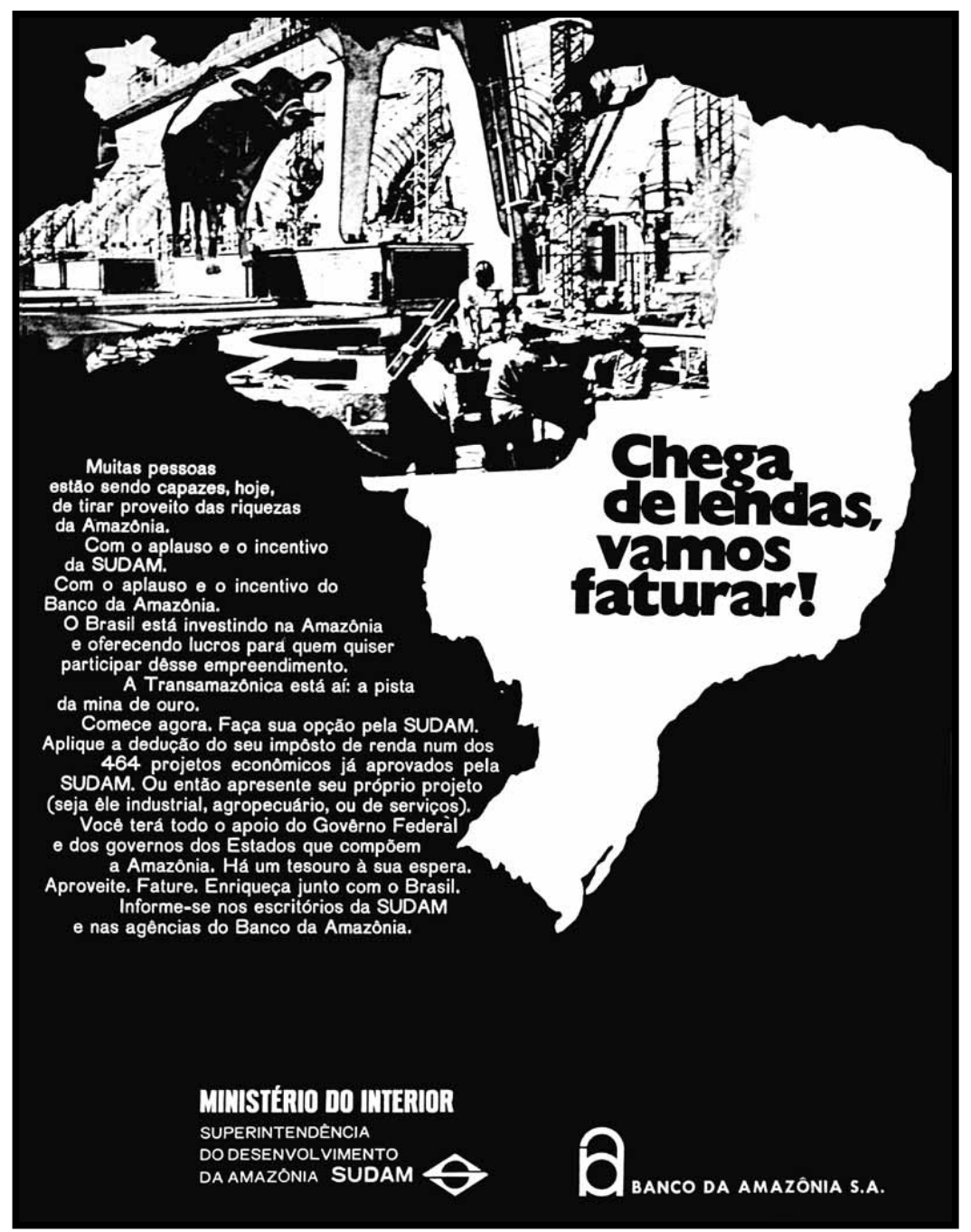

Fonte: Revista Veja (30/12/1970)

Percebam as intenções para a Amazônia, expostas na figura onde esta região se situa no mapa do Brasil: pecuária, industrialização, exploração mineral. Para que isso ocorresse, havia a necessidade do desmatamento. Percebam, também, que esta postura indica que esse olhar via a Amazônia como Periférica: "chega de lendas, vamos faturar". A Amazônia deixa de possuir um espaço vivido para ser um espaço de lendas, que precisa ser desmistificada pelo capital: "vamos faturar".

Então, esse olhar para a periferia, esse olhar periférico, foi fortemente trabalhado na Região Amazônica e fortemente assimilado por políticos locais, que até hoje continuam dizendo que a Amazônia é periférica; continuam dizendo que seus Estados integrantes são periféricos; continuam dizendo que se necessita das criações de novos Estados na região, pois se localizam na periferia e se está longe de tudo. Continuam com o mesmo discurso. Nesse 
sentido, observem que esse olhar periférico é um olhar político, principalmente por elites locais e pelo capital nacional.

Contudo, quando observamos esse mesmo olhar pelo capital internacional, perceberemos que há mudança de foco. Eles não utilizam o ser periférico somente, mas por ser estratégico. A reserva de manganês do Amapá, por exemplo, foi considerada uma reserva nacional (1946), por ser um minério estratégico naquela época. A partir da década de 1950, temos incentivos fiscais pelo Governo Federal, pelos seus órgãos de planejamento (SPVEA/Sudam; Suframa), principalmente ao capital internacional. Este entende que esta região deve ser vista com um olhar estratégico. Carajás tornou-se estratégico, as fronteiras tornaram-se estratégicas, a água tornou-se estratégica, a madeira tornou-se estratégico, o minério tornou-se estratégico.

Enfim, temos dois olhares no mesmo contexto, ou seja, a partir da década de 1970, a Amazônia já conectada, integrada e acionada (esta última expressão foi expressa pelo prof. Wilson Cano, Unicamp) pelo capital internacional fica cada vez mais estratégica. Gradativamente, a Amazônia deixa de ser periférica para se tornar um olhar mais intensamente da estratégia no cenário internacional.

Aquela mesma revista (Veja) 27 anos depois, toma outra postura. Divulga em sua capa não mais estimulando a integração pela lenha, começa a se preocupar também com a sua ameaça (Figura 2). Para ter-se uma ideia, na década de 1980, quando começou a expectativa de exploração do Carajás, era de 600 anos, hoje é de 180. As técnicas e as tecnologias usadas no uso deste território mineral se tornaram cada vez mais intensas e produtivas. A mesma situação ocorre na exploração do caulim, em Vitória do Jari (AP), área de influência imediata do Complexo Industrial do Jari, que estava estimada sua exploração para 400 anos, enquanto que hoje se pensa em 100 anos.

Então, aquele "Chega de lendas, vamos faturar" já foi faturado. Agora, a revista já começa a olhar a Amazônia como um "Tesouro Ameaçado". O interessante é que a revista expôs como símbolo da campanha uma vitória-régia (vegetação típica da região) queimada dentro de um lago, indicando que nem os rios ficaram fora da ameaça. 
Fig. 02. Capa de Revista Veja

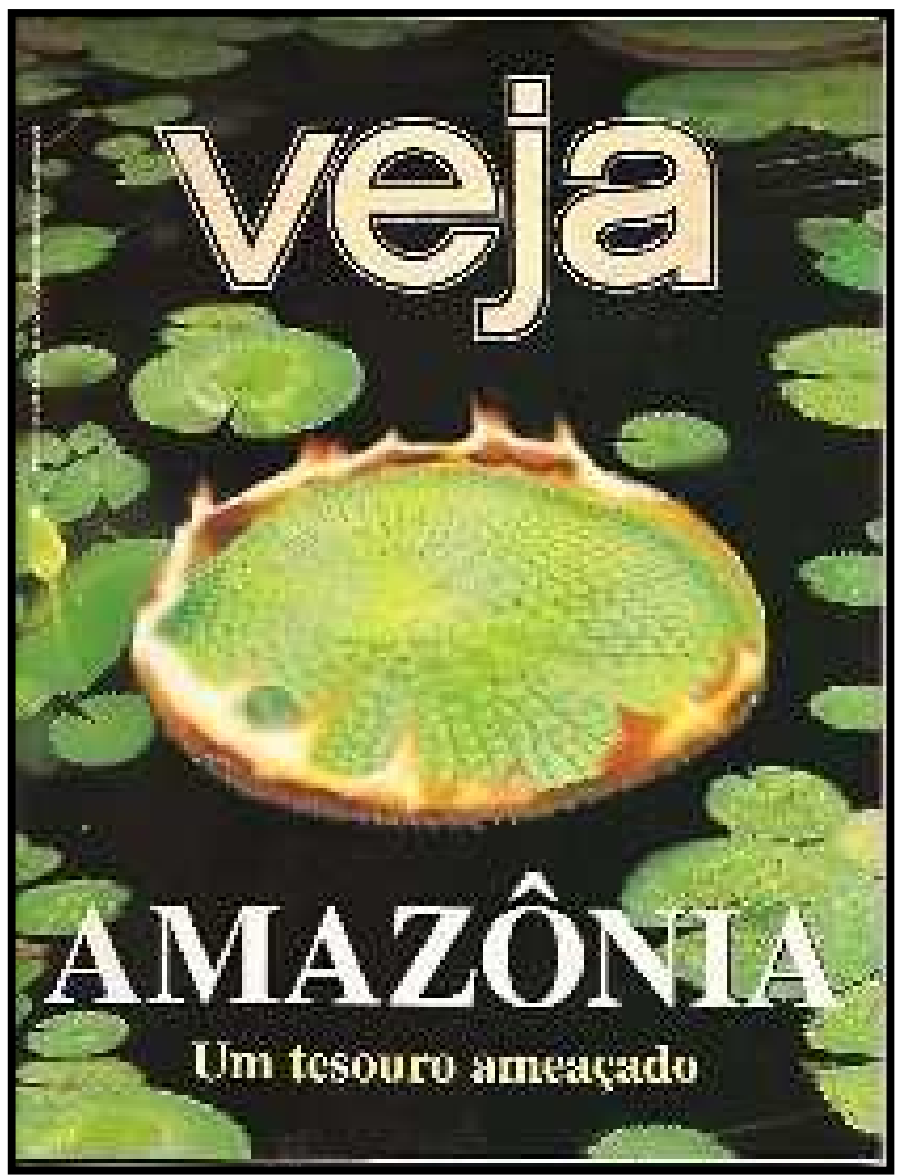

Fonte: Revista Veja, 24/12/1997.

Recentemente, em uma discussão ocorrida em sala de aula do Mestrado em Desenvolvimento Regional da Unifap, onde atuo, foi cunhada a expressão Efeito Avatar. Esse Efeito Avatar é uma referência ao filme dirigido por James Cameron Avatar, que discute a questão ambiental, as relações do capital em um espaço desprovido de tecnologia avançada, as estratégias para se alcançar a confiança da população local. Sobre este último, uma dessas estratégias é o explorador se transformar em um "azulzinho disfarçado",

Esse personagem conquista a credibilidade dos Na'vy. A imagem no filme mostrando que o explorador detém tecnologia, nesse caso o holograma tridimensional da árvore de morada dos Na'vys, indica muito bem que o capital sabe muito bem onde, como e quando atuar. Se pararmos para pensar, o acesso a imagens de satélite é muito semelhante ao contexto

\footnotetext{
${ }^{2}$ Expressão cunhada pela mestranda Christianni Soares (MDR/UNIFAP), ao lembrar o personagem humano que se disfarça como um nativo Na'vy para obter informações e confiança da população do planeta Pandora, convencê-los a se retirarem de seu local de habitação, a fim de acessar o unobitânium (metal de elevado valor no mercado).
} 
expresso na película. Com tais imagens, pode-se planejar, tomar decisões sobre como será usado o território.

Observem que temos unobitânium. Mas o interessante é que esse unobitânium também está localizado em áreas de reserva indígena para os $\mathrm{Na}$ ’y. Não temos árvores com aquelas dimensões, mas temos outras questões. Aquela árvore poderia ser muito bem uma reserva indígena aqui localizada. Da mesma forma como o "azulzinho disfarçado" identifica a Terra dos Na'vy como estratégico, ele almeja descobrir a localização exata dos produtos valorizados pela sua sociedade. A população local não reconhece o valor que ele afirma possuir, pois os valores de uso desses produtos são diferenciados entre os povos.

Vamos criar dois cenários aqui: um é o da Arábia e o outro é o da Amazônia. No primeiro onde está a riqueza? No subsolo (petróleo). Precisa-se de técnicas e tecnologias até chegar no petróleo. No caso da Amazônia, onde está a riqueza? Na biodiversidade e no subsolo.

Então, se for utilizar a técnica e tecnologia para aproveitar a biodiversidade, a potencialidade da Região Amazônica é elevada à enésima potência. Temos o unobitânium não somente no subsolo, mas também acima do solo, desde que sejam utilizadas a técnica e a tecnologia.

Observem então, com isso, outro aspecto da riqueza aqui localizada. Ela só foi acessada e não descoberta, porque foram construídas rodovias, ou seja, as cidades da Amazônia começam a ser construídas de costas para o rio, pelas rodovias. Hoje, acessa-se a Amazônia pelo rio e pelas rodovias. No acesso pelas rodovias, temos a aquisição de terras que outrora não eram atingidas.

Observem que continuam dizendo que a Amazônia é periférica e os nossos políticos locais, principalmente os que defendem essa ideia, mas, para o capital internacional, ela é extremamente estratégica. Descendo esse olhar para uma escala menor, no caso na escala do Amapá, veremos que existe somente uma rodovia que liga o Amapá do Norte ao Sul, do Oiapoque até o Laranjal do Jari. Nessa conexão, temos 16 municípios, sendo que a rodovia passa por 14 municípios do Amapá. Então o que eu fiz? Somente calculei a população residente nos municípios onde passa a rodovia, e não inseri no cálculo o eixo Macapá-Santana (Gráfico 1).

Gráfico 1. População Amapaense ao Norte e ao Sul do Eixo Macapá-Santana. 


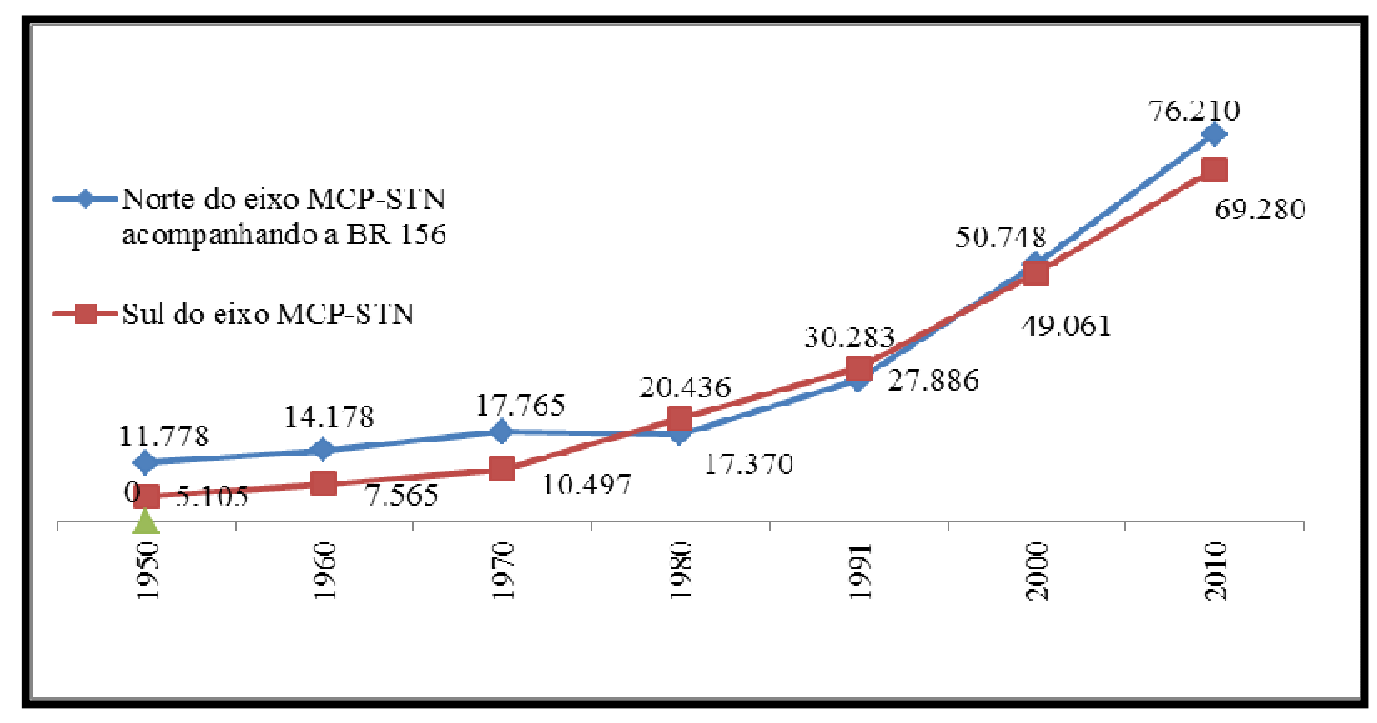

Fonte: IBGE, elaboração de Jadson Porto.

De 1970 a 1991, quando houve a instalação do Complexo Industrial do Jari, no sul do Amapá, foi quase que o mesmo período da construção da rodovia BR-156 (de 1970 a 1980), ligando o Oiapoque até o Laranjal do Jari. A partir da década de 1990, a ida para o Norte é mais intensa, pois, a partir de 1995, houve uma mudança de comportamento, principalmente representado pelo Acordo-Quadro entre Brasil e França. Esse Acordo visa à integração do Brasil com a Guiana Francesa, via Estado do Amapá, com as seguintes obras no lado brasileiro: pavimentação da rodovia BR-156 entre Oiapoque e Macapá e a construção de uma ponte binacional.

Essa mudança do Acordo-Quadro implicou em algumas mudanças. Em meados da década de 1990, se observa um aumento de empresas do mercado atacadista no Amapá. Com isso, lembro-me de uma obra do professor Álvaro Heidrich. Foi embasado nessa obra que eu montei essa reflexão. Está prevista a entrega da Ponte Fronteiriça construída entre a Guiana e o Brasil.

É a primeira ponte que unirá fisicamente esses dois territórios. Já na Região Sul, há várias pontes ligando o Brasil a outros países. Por isso, considerando que o Sul do Brasil já possui uma conectividade intensa entre esses territórios, entre o Amapá e o Platô das Guianas essa conectividade será iniciada somente no segundo decênio do século 21. A construção desta ponte afetará imediatamente o Porto de Santana, pois a Guiana Francesa tem uma forte ligação com as ilhas do Caribe. Com essa instalação, acredita-se que haja uma mudança de 
eixo favorável ao Amapá, pois a relação das outras fronteiras com o Brasil é diferente em relação à Guiana Francesa.

Embora o Amapá possua fronteira com o Suriname, não há conectividade física rodoviária entre ambos. Isso somente ocorre com a Guiana Francesa. Com isso, sua interação cambial fronteiriça é a relação Euro-Real, onde o Euro é mais forte que o Real. Nas outras fronteiras, o Real é mais forte do que a moeda dos outros países. Ou seja, é uma relação inversa, pois é o único contato fronteiriço onde o Brasil possui a moeda fraca. Outro aspecto digno de citação, para reflexão futura, diz respeito à condição do Amapá como vizinho da União Europeia (por consequência, a todas as questões administrativas, políticas e econômicas inerentes à sua condição de ultraperiferia deste Bloco) e à Organização do Tratado do Atlântico Norte (OTAN).

Desde a década de 1990, há uma ampliação das empresas no mercado atacadista, onde eram 4, e, em 2009, passaram para 44. Esta conectividade tem sido muito estimulada para o Norte da América do Sul. Na década de 1990, também foi instalada a Área de Livre Comércio Macapá e Santana, uma das sete Áreas de Livre Comércio instaladas na Região Amazônica. Essa foi a única que conseguiu avançar, as demais, não. Em 2008, foi criada a Zona Franca Verde, localizada no município de Santana.

Outra discussão sobre a condição fronteiriça amapaense diz respeito às restrições de uso do território amapaense. Hoje, mais de 70\% do território do Amapá possui algum grau de restrição de uso do território: Unidades de Preservação, Reservas Indígenas e a criação da floresta estadual. O que isso implica no território?

Eu tenho um Estado juridicamente delimitado, mas que não possui terras. Eu tenho um Estado cujas terras são administradas pelo Instituto Chico Mendes, pela Funai, pelo Incra, e a faixa de fronteira que é uma faixa de segurança nacional. Isso implica em efetivações constantes e novas pactuações sobre o uso do território amapaense. Eu costumo de dizer que o Amapá tem cinco dirigentes: o Diretor do Ibama, o da Funai, o do Incra, o Comandante do Exército e o Governador do Amapá, sendo este último eleito pelo povo. O Governador do Amapá possui o controle de $1 \%$ do território amapaense. Existe o controle de terras, mas essas não estão regulamentadas, o que causa uma grande confusão no Amapá.

Quanto à urbanização amapaense, isso significa um impacto no PAC nacional. Além disso, a construção da ponte binacional, a pavimentação da BR-156, a recuperação da economia mineira e os reflexos dessas atividades no Porto de Santana estimularão, como já estimularam até agora, a prostituição no Oiapoque e no Porto de Santana e as doenças 
venéreas na região dos índios. Para olharmos a questão da fronteira, temos que levar em conta todas essas questões sociais que envolvem a região.

Nesse sentido, vemos qual condição fronteiriça é essa a do Amapá. Foi falado que o Amapá possui uma posição periférica, mas essa posição não é somente porque ela é localizada longe dos centros das decisões políticas e econômicas; ou é uma fornecedora de commodities; ou possui uma precariedade viária (acessibilidade, mobilidade, fluidez); ou possui baixo nível de mão de obra; ou a magnitude do Estado é grande, mas fraca; ou detém um baixo índice de industrialização (falta de elite industrializante).Todos esses fatores juntos estimulam a visão do Amapá periférico. Se olharem a literatura, perceberão que as pessoas não conseguem ver o Amapá dentro de um conjunto, mas sim em partes.

Então, o Amapá possui o seu capitalismo tardio periférico da periferia, pois ele possui um baixo nível de tecnificização, cujas técnicas rígidas a partir da década de 1950, com a empresa Icomi, tornaram-se mais flexíveis com o Complexo do Jari. O interessante é que esse complexo insere o Amapá dentro desse contexto mais flexível. O Amapá é estratégico porque: ele é produtor e fornecedor de matéria-prima, pois o capital encontra-se ali para explorá-lo e explotá-lo; encontra-se na Região Amazônica; localiza-se na foz do Rio Amazonas, onde tem alimentos, minérios; está próximo dos países industrializados.

Desde a sua estadualização, o Amapá é construído em cima de expectativas. O Amapá é limitado devido às condições já citadas anteriormente. Assim, a condição fronteiriça amapaense não é periférica e nem estratégica. Ela é periférico-estratégica em determinados momentos como também é estratégico-periférica para outros. Mudando as palavras, mudamos também o sentido, o objetivo do objeto. A condição fronteiriça nesse contex to é decorrente de três fatores: i) da participação do Governo Federal, criando condições para a mobilidade e reprodução do capital; ii) da articulação das redes criadas/construídas em um espaço poroso, e iii) na atuação do capital internacional na exploração de commodities, com o estímulo do Estado, e no atual uso do território fronteiriço.

Com a grande atuação do Governo Federal na Amazônia e nos ex-Territórios Federais, houve investimentos pesados que consolidaram a magnitude do Estado naquela região. $\mathrm{O}$ Amapá é articulado em redes espaciais por parte do Programa de Faixa de Fronteira. Existem 750 quilômetros de fronteira sem controle do Estado. As grandes empresas instaladas no território amapaense ficaram entre os cem maiores investimentos do Brasil, desde a década de 1970. Portanto, o Amapá não é periferia, não é um estado pequeno. Se fosse pequeno, o grande capital não estaria lá. 
O Amapá possui outra articulação. É a articulação de cidade pequena global, que possui uma conectividade de redes globais, como são os casos de Pedra Branca do Amapari, que exporta o ouro para os Estados Unidos; de Serra do Navio, que manda o manganês para o cenário internacional; de Vitória do Jari, que exporta o caulim para ser beneficiado no Pará, na outra margem do Rio Jari (Munguba/Almerim).

Vitória do Jari e Pedra Branca do Amapari estão entre os 14 municípios que mais recebem recursos da Compensação Financeira pela Exploração de Recursos Minerais (CFEM) no país, mas os investimentos locais necessitam de uma melhora de gestão. A condição fronteiriça também está na atuação do capital. Então, temos o poder político, o capital internacional e as suas articulações, com as redes globais - a condição fronteiriça está assentada nesses três elementos.

Quanto à importância do Porto de Santana às condições estratégicas da fronteira amapaense, destacam-se as suas vantagens comparativas de sua localização, tais como: possui capacidade de receber navios com 11 metros de calado (semelhante aos principais portos sulamericanos), enquanto que, na Guiana Francesa, atinge no máximo 5 metros. O porto está próximo aos grandes centros industriais (EUA, Europa e Ásia - pelo Canal do Panamá); e não está na área de ocorrência de furacões, perigos constantes dos portos do Caribe, conforme nos lembra o Coordenador de Desenvolvimento Tecnológico e Inovação, da Secretaria de Ciência e Tecnologia do Estado do Amapá, Celso Correa Soares.

Considerando a calagem do sistema portuário da Guiana Francesa, a construção da ponte binacional é uma alternativa que deve ser levada em consideração, pois o custo de sua construção é inferior às dragagens constantes neste sistema. Com isso, estima-se que o eixo das relações econômicas da Guina Francesa com o Amapá tende a mudar, estimulando os fluxos de bens e mercadorias a este espaço ultraperiférico francês, tendo por apoio o sistema portuário de Santana (AP).

É pelo Porto de Santana que as exportações de madeira, alimentos (açaí) e minério saem para o mercado mundial, notadamente para os Estados Unidos e a Europa. Para o caso do Complexo Industrial do Jari, suas exportações saem pelo Porto de Munguba (Almerim PA).

Por outro lado, quando se buscam informações sobre as exportações para a Guiana Francesa, verifica-se que inexistem dados oficiais sobre isso. Mas percebemos, em nossos trabalhos de campo, que os setores de alimentos (carnes, frutas, peixe, farinha) e de produtos industrializados e negociados pelos supermercados e comércios atacadistas são amplamente 
distribuídos em comércios locais da Guiana Francesa. Tal situação se deve à diferença cambial entre o Euro e Real, fazendo com que o comerciante guianense compre no Brasil produtos mais baratos.

Encontramos no Amapá uma relação híbrida dos circuitos superior e inferior da economia, circuitos esses trabalhados pelo mestre Milton Santos. Ou seja, temos uma exportação internacional informal, sem controle e fiscalização do Estado. O circuito superior trabalha com as relações oficiais. $\mathrm{O}$ circuito inferior trabalha com as relações locais e informais, e o caso da Guina é uma exportação local informal.

Vejamos um caso recente divulgado nos jornais amapaenses (julho de 2010). O Suriname assinou um acordo com o Amapá, no qual aquele vai importar material de construção do Amapá. Considerando que só existe uma via de acesso do Amapá para a fronteira e que, para se chegar ao Suriname, obrigatoriamente precisa passar pela Guiana Francesa, então existe uma possibilidade de comerciantes da Guiana Francesa virem comprar material de construção no Amapá para exportar para o Suriname. Ou seja, comprarão produtos em Real e venderão em Euro.

O Porto de Paramaribo (capital de Suriname) possui 11 metros de calado, semelhante ao de Santana (AP). Por que, então, se tem aproximação da Guiana Francesa com o Amapá? Dentre algumas explicações de ordem política, que poderíamos discuti-las profundamente em outro momento, ater-me-ei à condição industrial brasileira. O Brasil é um país industrializado e o Suriname, não.

Então, temos vários estímulos para essa relação transfronteiriça que estão em processo de construção. Em 1995, foi assinado o Acordo-Quadro. Em 1996, foi ampliado o Porto de Santana. O Acordo-Quadro dizia que a Guiana Francesa construiria uma rodovia ligando Caiena até Saint George, e o Brasil seria responsável pela pavimentação da rodovia no lado brasileiro. Até hoje dos 600 quilômetros previstos para pavimentação, só 250 quilômetros foram pavimentados.

Para finalizar minhas reflexões, entendo que a atual condição fronteiriça amapaense é:

- diretamente ligada aos movimentos de construção e (des)territorialização, constante e fortemente integrada à ação do Estado;

- $\quad$ ligada a resultados das instalações de próteses, segundo a visão miltoniana;

- $\quad$ está relacionada à existência, à configuração e à intensidade de articulação de diversas relações;

- é estimulada por expectativas; 
- é construída em um espaço com extensas áreas de restrição de uso do território, significando que a população não pode ir para o interior do Estado, fazendo com que a população seja urbana;

- $\quad$ é estabelecida como fornecedora de commodities;

- não possui estímulos ao processo de industrialização, porque, no Amapá, não existe uma elite industrializante forte o suficiente para romper a condição anterior, mas corrobora para estimular uma elite industrializada, que consome somente produtos industrializados, mas não estimula o processo de industrialização.

Outra abordagem a ser chamada a atenção nesta condição diz respeito às tensões e contradições multiescalares. É interessante entender que o Amapá faz parte de uma política de ordenamento territorial internacional, pelo Iniciativa para a Integração da Infraestrutura Regional Sul-Americana (IIIRSA) e pelo Programa Operação Amazônia da União Europeia, onde a ponte binacional, a pavimentação rodoviária guianense e amapaense e o Porto de Santana fazem parte desta política.

No que tange às interações espaciais fronteiriças em questão, percebemos que há acordos diplomáticos e relações locais. No século 20, o primeiro acordo direcionado à Guiana Francesa ocorreu com a arbitragem internacional em 1900, reconhecendo o Rio Oiapoque como a fronteira entre Brasil e Guiana Francesa. Depois disso, só em 1995 (com o AcordoQuadro), ou seja, passou o século 20 inteiro sem se construir uma relação diplomática entre Brasil e França sobre o Platô das Guianas.

Contudo, as relações locais sempre existiram, mas as construções efetivadas não foram respeitosas ao povo brasileiro. As brasileiras são vistas como prostitutas e os brasileiros como vagabundos ou mão de obra para trabalhar em serviços mais pesados, de baixa qualificação. Isso na visão dos habitantes da Guiana Francesa. Ou seja, o que existiria outrora era uma fronteira restrição.

Na segunda metade da década de 1990, uma nova construção de fronteira é estabelecida: a fronteira de cooperação. Entretanto, não será em dez anos que isso removerá as questões culturais de restrição estabelecidas desde o período colonial. Vai demorar muito mais do que isso, pois não somos mais um espaço de separações. Vale ressaltar diante deste aspecto que outrora tínhamos o rio e uma floresta que nos separava. Hoje, essas barreiras físicas foram conquistadas pelas rodovias no lado francês e no lado brasileiro. O Platô das Guianas está conectado. 
O Amapá mudou de periférico nacional para estratégico internacional, de fronteiriço desconectado para articulado, de espaço de expansão para espaço de restrição e, nesse sentido, essa fronteira-rede interage para articulada globalmente.

Obrigado pela oportunidade de trazer algumas reflexões e estimular uma discussão fronteiriça do Oiapoque ao Chuí. 